\author{
MILITARY TECHNICAL COLLEGE \\ CAIRO - EGYPT
}

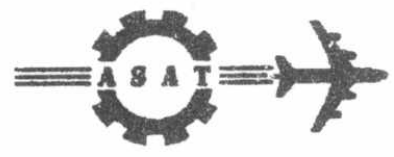

$7^{\text {th }}$ INTERNATIONAL CONF. ON AEROSPACE SCIENCES \& AVIATION TECHNOLOGY

\title{
INVESTIGATION OF HELICOPTER STABILITY \\ CONSIDERING THE EFFECT OF ITS HYDRAULIC SERVOACTUATOR AND AUTOPILOT
}

\author{
SAMIR M.M.* KATARY M.A.** RABIE M.G.** *
}

\begin{abstract}
The control system of a helicopter, including a hydraulic servoactuator, HSA, and an autopilot is investigated. The dynamic behavior of HSA is studied theoretically and experimentally. A nonlinear mathematical model and a computer simulation program are developed for the HSA and validated by comparing experimental and theoretical results. A second order transfer function for the HSA is also deduced by using the simulation program. A mathematical model for the hovering helicopter is developed and used to deduce the helicopter transfer function. The helicopter is found to be unstable in hovering, it could be stabilized either through the pilot action or by using an autopilot. An autopilot is designed to assure the system stability. The transient response of the helicopter equipped with the HSA and the proposed auto pilot is investigated. The effect of some operational parameters on the HSA and helicopter dynamics is studied theoretically. The results showed that the autopilot insures the required helicopter stability and reduces substantially the effect of certain HSA defects, such as the increase in internal leakage.
\end{abstract}

\section{KEY WORDS}

Helicopter - hydraulic - Servoactuator - Autopilot - Stability - Hovering - Transfer function.

Capt. Eng., Air force Research and Development Center.

** Assoc. Prof., Air force Research and Development Center.

|*** Professor, Aeronautical Department., MTC, Cairo. 


\section{NOMENCLATURE}

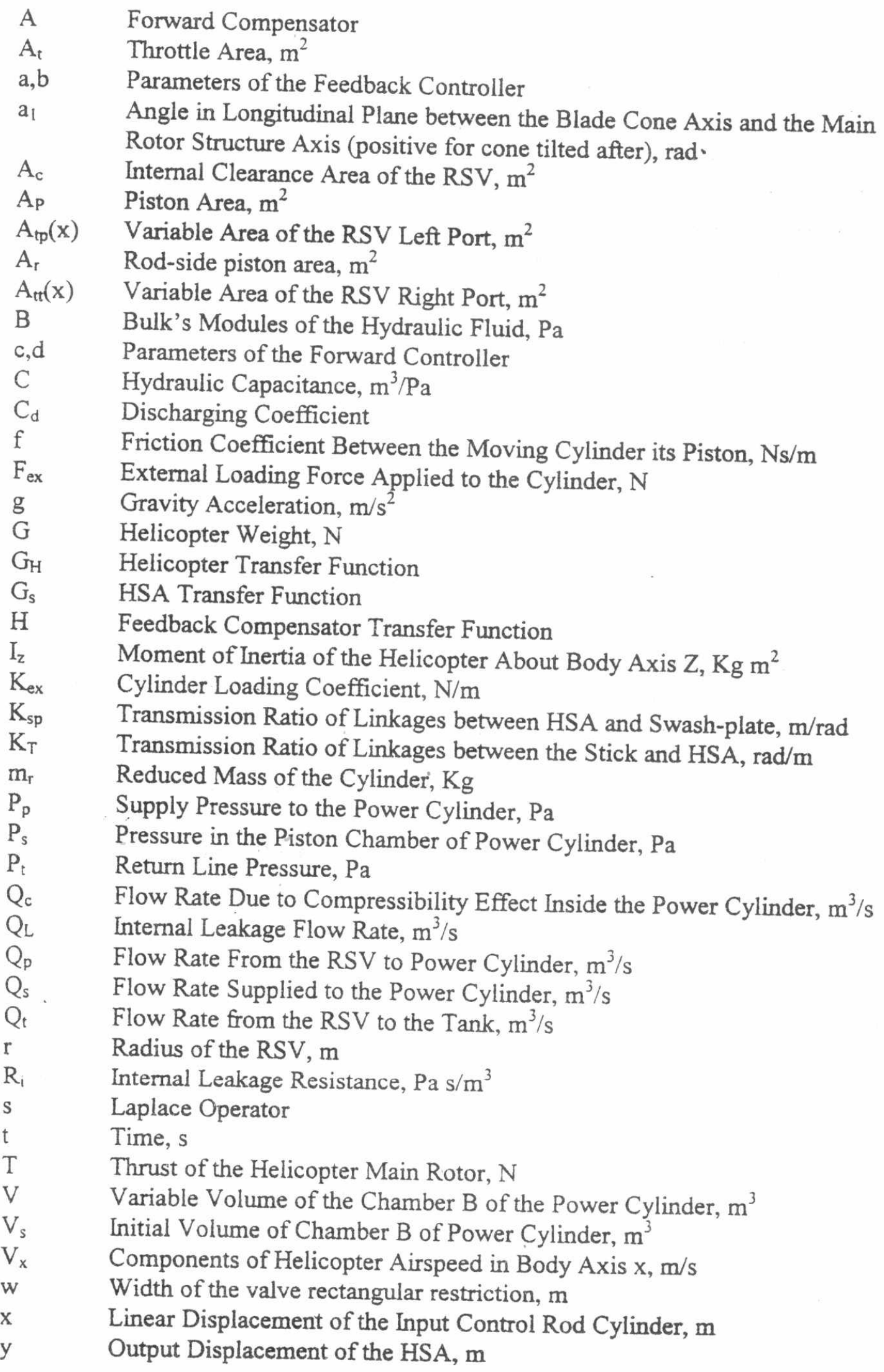


$y_{\varepsilon} \quad$ Effective Hub Height above Helicopter C.G, m

z Input Displacement to the HSA, m

$z_{m} \quad$ Magnitude of Step Input, $m$

$\Delta \mathrm{P} \quad$ Pressure Difference, $\mathrm{Pa}$

$\rho \quad$ Fluid Density, $\mathrm{Kg} / \mathrm{m}^{3}$

$\theta \quad$ Pitch Angle of Helicopter, rad

$\alpha \quad$ Rotation of the RSV Opening, rad

$\delta_{z} \quad$ Deflections of Swash-blade (Longitudinal Control), rad

\section{ABBREVIATION}

HCS Helicopter Control System

HSA Hydraulic Servo Actuator

RSV Rotary Spool Valve

\section{INTRODUCTION}

In recent years, the complexity of control systems for flying vehicles increases in connection with the advances in flight performance. The helicopter is no exception in this regard. The early helicopters control systems consisted only of mechanical linkages and mechanisms for deflecting the control organs. The later systems included hydraulic boosters to relieve the control loads. Modern helicopter control systems include automatic stabilization devices (auto-pilots, rpm controllers) to provide semi automatic and automatic piloting of the helicopter.

The modern concepts in designing helicopters control system is the tendency toward combining devices performing various functions into integrated units. This concept reduces the system weight and power required to drive such a system., The interaction of hydraulic boosters with the auto-pilot servos is an example, toward increasing integration of the control system with the entire complex of piloting and navigation equipment.

The installation of Hydraulic Servo Actuator is important for the controllability and maneuverability. The HSA operates most of the time in the transient regime, therefore, the constructional and operational parameters that affect directly the HSA performance were the field of study of numerous publications [1] to [5]. Also, the stability and controllability of helicopter is discussed in several references, [6] to [10].

This work deals with the analysis of the stability of helicopter during hovering mode, considering the effect of constructional and operational parameters of the used HAS. 


\section{2-MATHEMATICAL MODEL OF HYDARLIC SERVOACTUATOR}

\subsection{Description Of Helicopter Control System}

The study is applied to helicopter Gazelle type SA 341. The flying controls are designed to act on the incidence angle of the main and tail rotor blades. They allow the helicopter attitude, heading and altitude to be controlled. The flying controls comprise three linkages, one for the lateral and longitudinal cyclic pitch control, one for the collective pitch control and one for the tail rotor pitch control. The controls are of the rigid type (control rods) for the first two linkages and of mixed type (rods and cables) for the third one. Three hydraulic servoactuators are used to displace the swash-plate (two for lateral control and one for longitudinal control). These servo actuators are of the single sliding body type. Manual control is possible in case of failure of the hydraulic power system by locking the input mechanism.

\subsection{Main HSA of The Helicopter}

The main servo control unit is installed between the main gear box fixed housing and the swash-plate. The moving part of the HSA is connected to the swash-plate, and the fixed part is attached to the main gear box housing. The HSA, Fig.1, consists essentially of a power cylinder (6), which comprises:

- A single rod hydraulic cylinder.

- Directional control valve with rotating spool value, RSV (5)

- Bypass valve(2)

The piston rod chamber, $A$, is in permanent connection with the pressure line through the valve housing and the fixed sleeve. The connection of the piston chamber $B$ with the pressure and return lines is controlled by the spool valve.

\subsection{Mathematical Model of HSA}

The assumptions considered in deducing the mathematical model of the HSA are as follows:

1- There is no external leakage.

2-The effect of elasticity of the cylinder walls is neglected

3- The inner hydraulic transmission lines are of negligible effect on the behavior of the HSA.

4- The feedback mechanism is of negligible inertia.

The following mathematical relations describing the HAS, Fig.2, could be deduced.

\subsubsection{Flow Through RSV Opening.}

The RSV is of zero lapped type. The valve restriction area is controlled by the spool rotation angle $\alpha$. For the small rotational angles, characterizing the normal operation of the valve, the valve restriction area could be given by the following expression. $A(\alpha)=w r \alpha$

Where $w$ is the width of the rectangular valve port. The flow rates through the RSV restriction areas, are given by the following relations.

$$
Q_{p}=C_{d} A_{t p}(x) \sqrt{\frac{2}{\rho}\left(p_{p}-p_{s}\right)}
$$




$$
Q_{t}=C_{d} A_{t t}(x) \sqrt{\frac{2}{\rho}\left(p_{s}-p_{t}\right)}
$$

Where for $\quad x \geq 0 \quad A_{t p}(x)=w x+A_{c}$, and $A_{t t}(x)=A_{c}$

$$
\mathrm{x}<0 \quad \mathrm{~A}_{\mathrm{tp}}(\mathrm{x})=\mathrm{A}_{\mathrm{c}} \text {, and } \quad \mathrm{A}_{\mathrm{t}}(\mathrm{x})=-\mathrm{wx}+\mathrm{A}_{\mathrm{c}}
$$

\subsubsection{Continuity Equation Applied to the piston chamber}

The following is continuity equation applied to the piston chamber B, Fig. (2).

$$
2 Q_{p}-2 Q_{1}-A_{P} \frac{d y}{d t}-\frac{P_{p}-P_{S}}{R_{i}}-\frac{V_{S}+A_{P} y}{B} \frac{d P_{S}}{d t}=0
$$

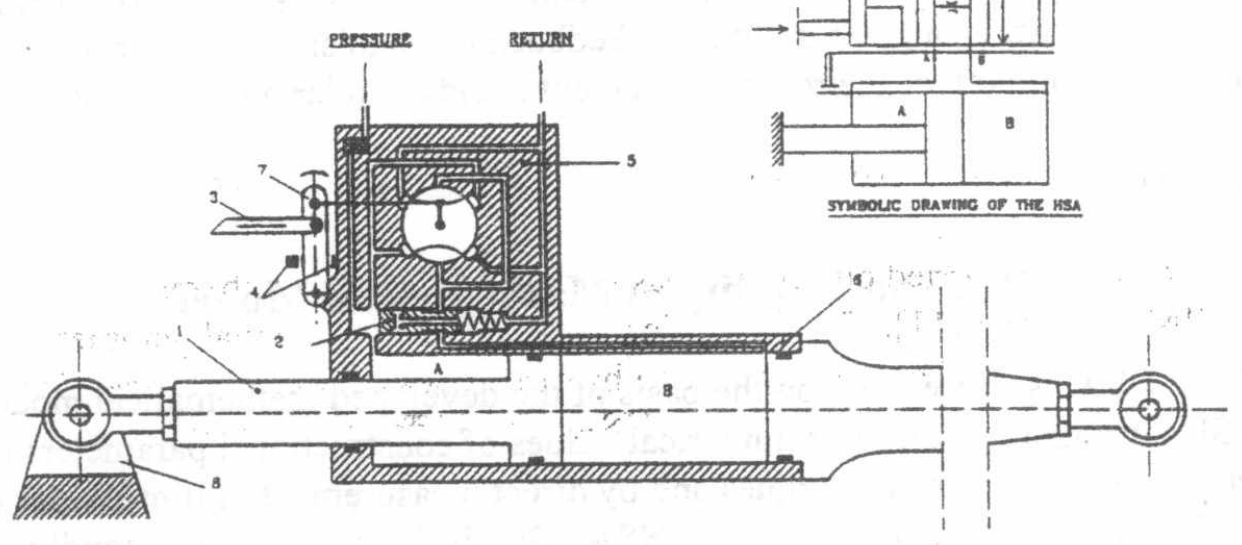

1. Power piston

4. Displacement limiter

7. Feedback lever
2. By-pass spool valve

5. Rotating spool valve

8. Gear box housing
3. Input lever

6. Power cylinder

Fig.1. Scheme of the main Hydraulic Servoactuator

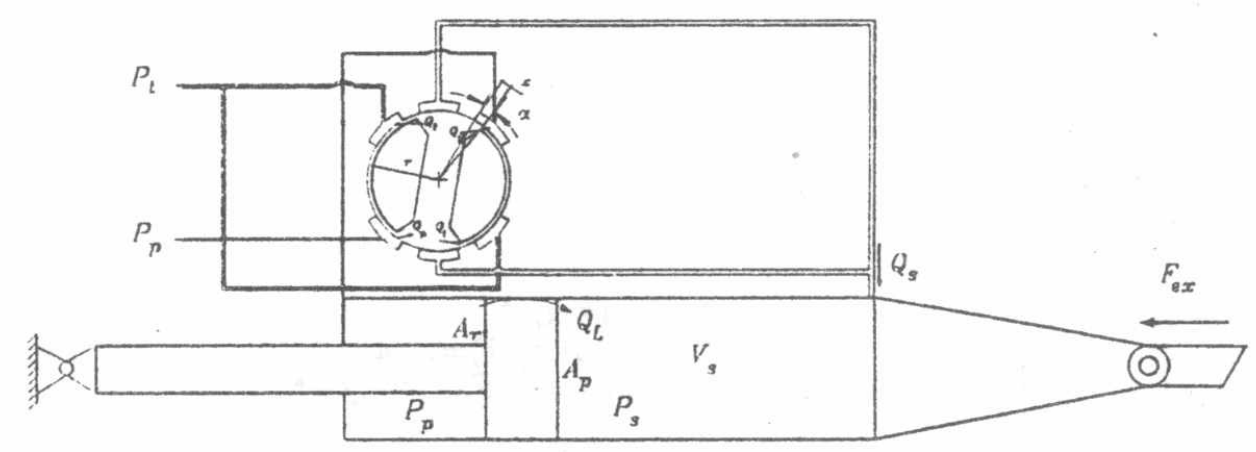

Fig.2. Functional schematic of the HSA 


\subsubsection{Equation of Motion of cylinder}

The piston rod is fixed and the cylinder displaced under the action of the forces acting on it. The loading force $F_{e x}$ is assumed to change linearly with the cylinder displacement; $F_{e x}=K_{e x}$. The equation of motion of cylinder is given as follows:

$$
P_{s} A_{p}-P_{p} A_{r}=m_{r} \frac{d^{2} y}{d t^{2}}+f \frac{d y}{d t}+F_{e x}
$$

\subsubsection{Feed Back Equation}

The HSA is controlled by the rotation angle $\alpha$ of the spool of its directional control valve. The angle $\alpha$ is affected by the linear displacement $z$ of control rod. The cylinder displacement $y$ affects also the spool rotation angle, through the feedback mechanism. The relation between the spool rotation angle and both of the rod displacement $\mathrm{z}$ and cylinder output displacement $\mathrm{y}$ is found to be:

$$
x=0.8(z-y)
$$

\subsection{Simulation of the HSA and Validity of Mathemetical Model}

The simulation of HSA is carried out, on the basis of the developed mathematical model, by using the TUTSIM program [11]. The numerical values of constructional parameters of the HSA have been found from the catalogues and by direct measurement of dimensions of its basic elements. The transient response of the HSA, for different operating conditions, is plotted in Figs. 3, 4 \& 5.

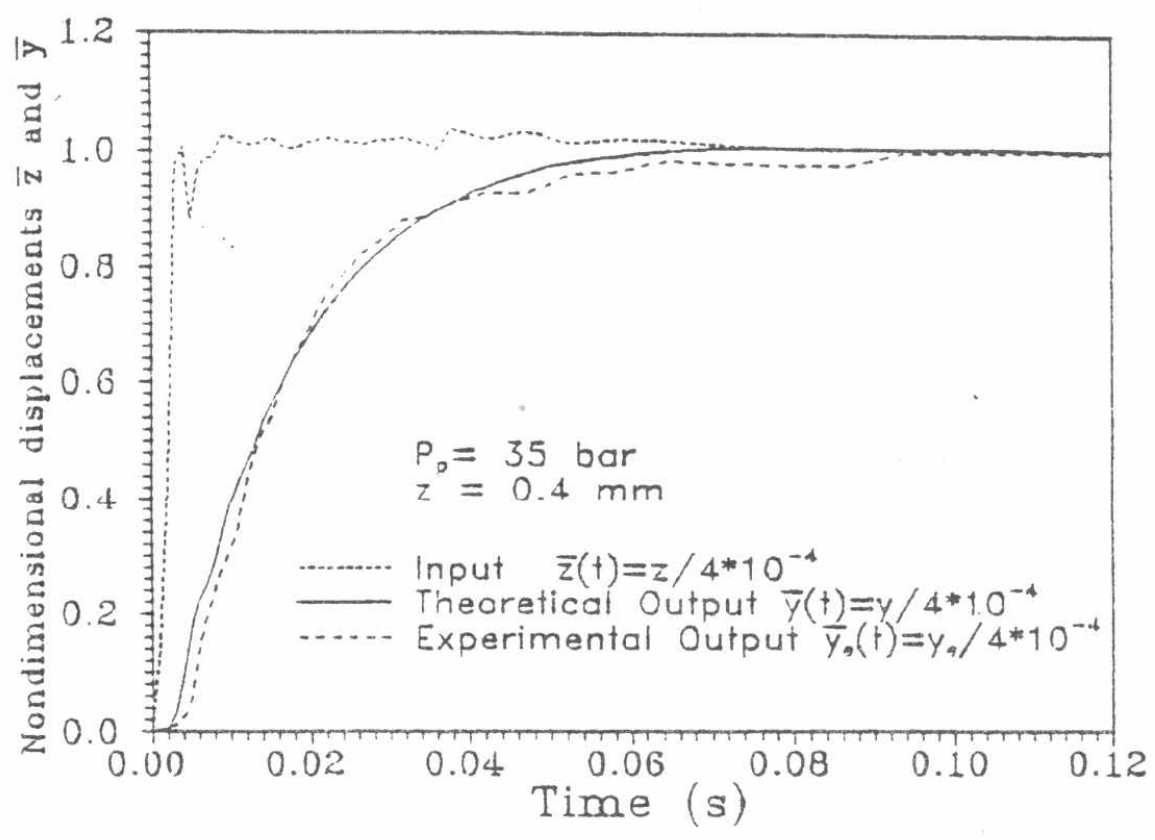

Fig.3. Simulation and experimental results of transient response of HSA at 35 bar supply pressure and $0.4 \mathrm{~mm}$ step input displacement 


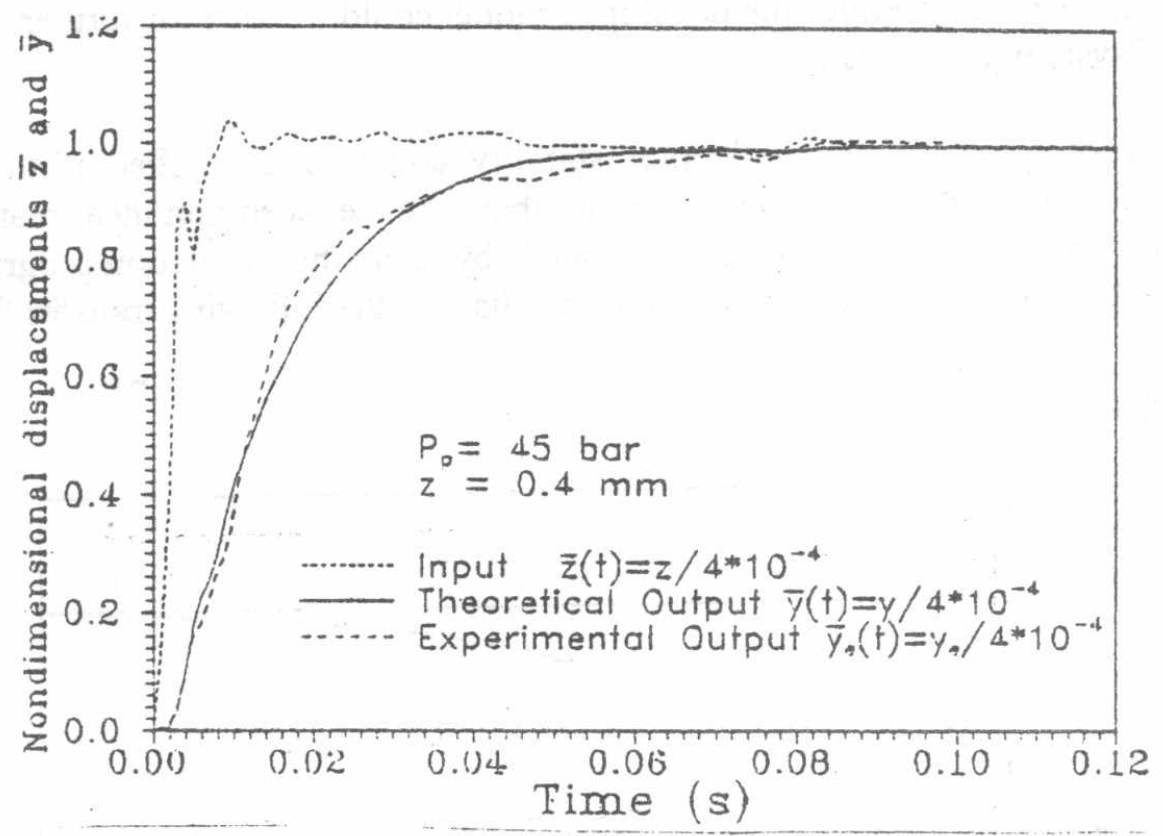

Fig.4. Simulation and experimental results of transient response of HSA at 45 bar supply pressure and $0.4 \mathrm{~mm}$ step input displacement

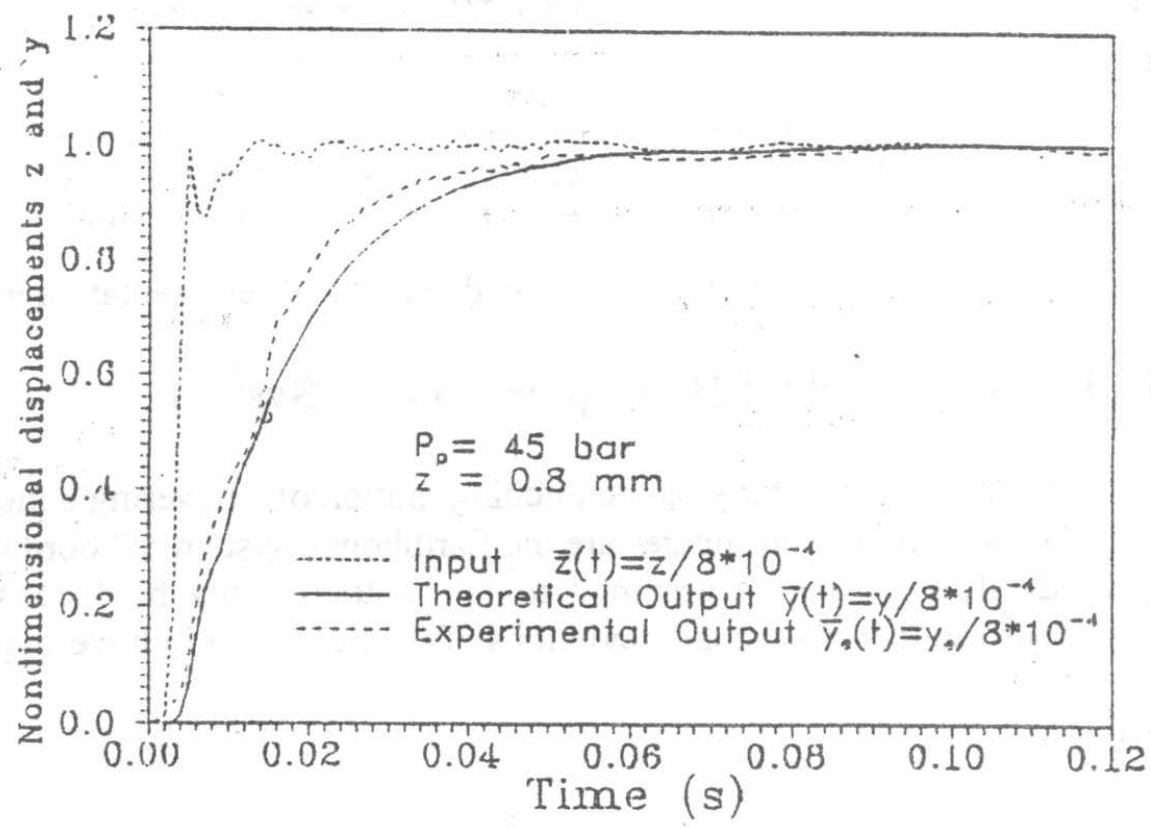

Fig.5. Simulation and experimental results of transient response of HSA at 45 bar supply pressure and $0.8 \mathrm{~mm}$ step input displacement 
The experimental work is directed to check the validity of the deduced mathematical model describing the HSA. The transient response of the HSA is evaluated experimentally and plotted in Figs.3, $4 \& 5$. These figures show acceptable agreement between the experimental and simulation results from the point of view of general shape of response, settling time, rise time and steady state error. Therefor the developed model could be used for further theoretical investigations of system performance.

The further investigation of the helicopter stability could be simplified if the HSA is represented by a simple transfer function rather than the deduced nonlinear mathematical model. The Step response of the HSA, calculated by using the simulation program, Fig.6, showed that the HSA behaves as a first order element having the following transfer function.

$$
\frac{y}{z}=\frac{1}{0.02 s+1}
$$

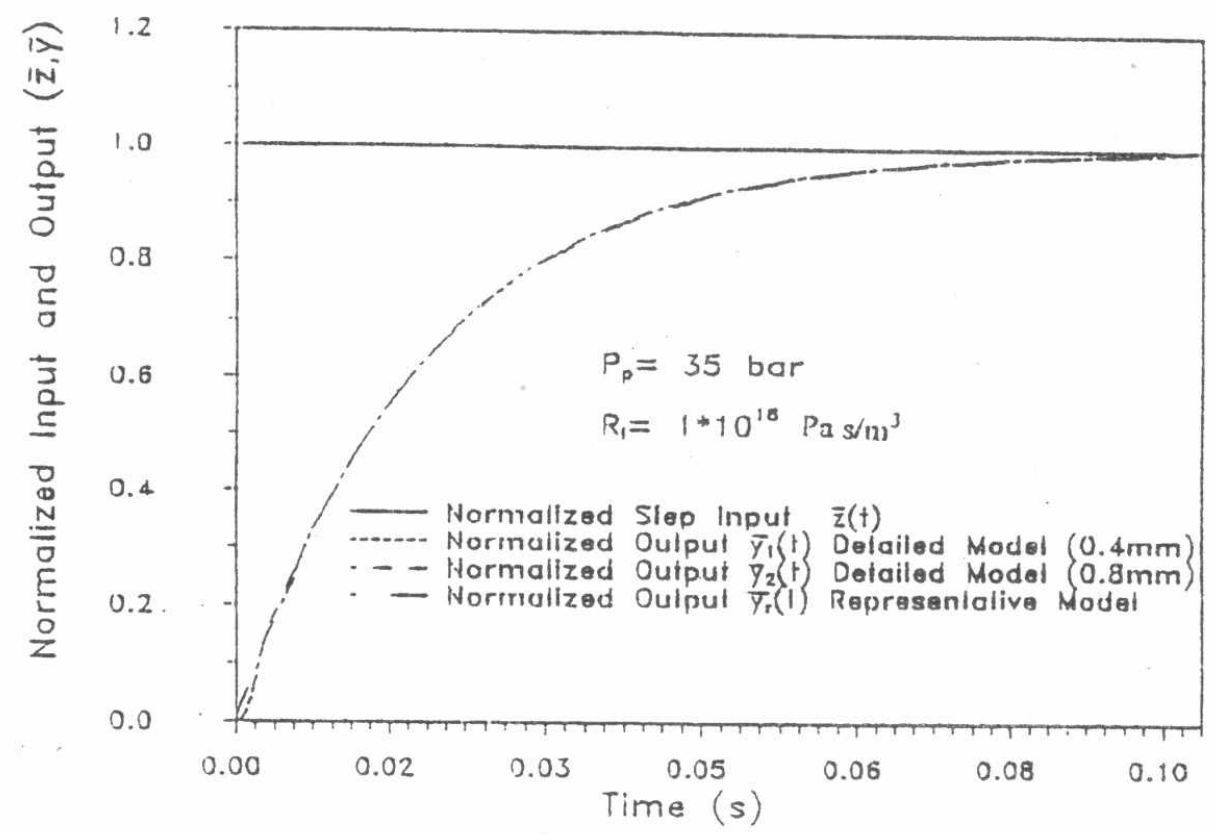

Fig.6. Step response of HSA calculated b using the detailed and representative models.

\section{MATHEMATICAL Model Of Helicopter Control System}

The flight mode, considered in this study, is the pitching motion of a hovering helicopter in a calm wind Fig.7. The system of coordinates are the Earthbound system of coordinates. The angular velocity of the lifting rotor is assumed to be automatically held constant. The equations of motion corresponding to small deviations of the helicopter in hovering mode [1] are:

$$
\begin{aligned}
& \mathrm{I}_{z} \Delta \ddot{\theta}=\mathrm{TY}_{\varepsilon} \Delta \mathrm{a}_{1} \\
& \frac{\mathrm{G}}{\mathrm{g}} \Delta \dot{\mathrm{V}}_{\mathrm{x}}=-\mathrm{T}\left(\Delta \theta+\Delta \mathrm{a}_{1}\right)
\end{aligned}
$$

Where $\Delta \mathrm{a}_{1}$ is the inclination angle of the lifting rotor resultant force.

$$
\Delta \mathrm{a}_{1}=\Delta \mathrm{a}_{1 \mathrm{v} x_{\mathrm{x}}}+\Delta \mathrm{a}_{1 \omega_{\mathrm{z}}}+\Delta \mathrm{a}_{1 \delta_{\mathrm{z}}}
$$



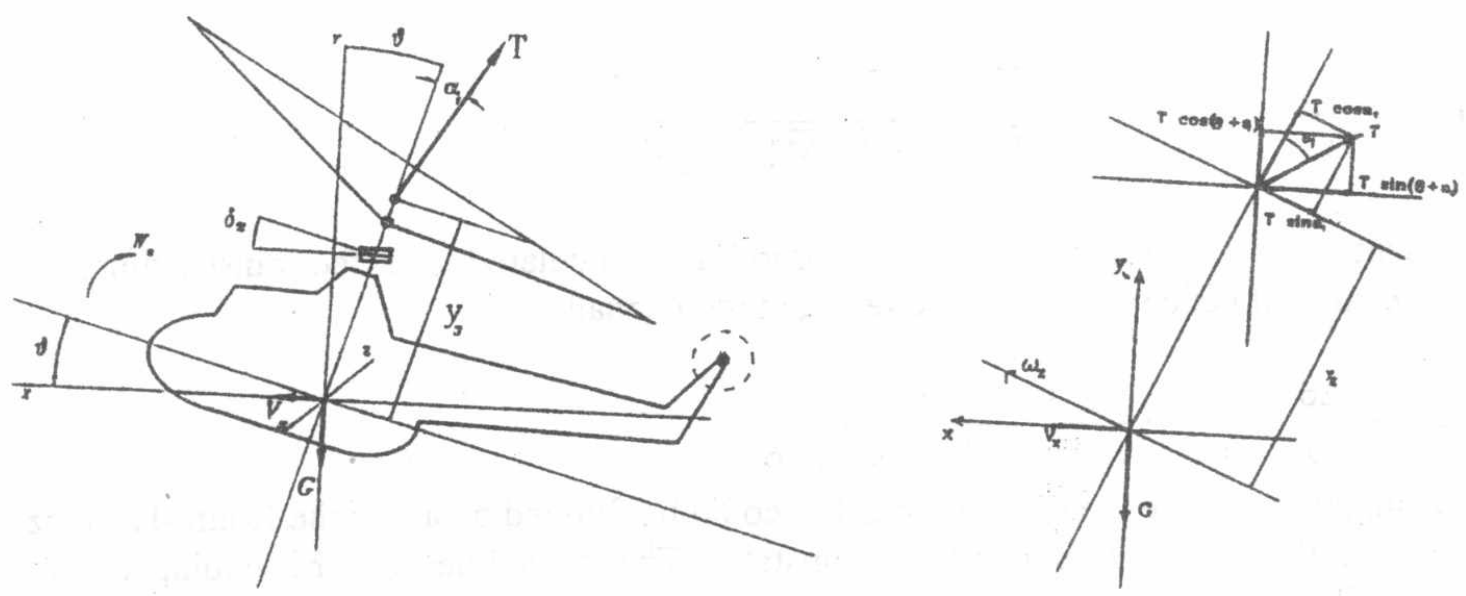

Figure (7) Forces Acting on Hovering Helicopter

$$
\Delta \mathrm{a}_{1 \mathrm{v}_{\mathrm{x}}}=\mathrm{a}_{1}^{\mathrm{v}_{\mathrm{z}}} \Delta \mathrm{v}_{\mathrm{x}}, \Delta \mathrm{a}_{1 \omega_{z}}=\mathrm{a}_{1}^{\omega_{z}} \Delta \dot{\theta} \text { and } \Delta \mathrm{a}_{1 \delta_{z}}=\mathrm{a}_{1}^{\delta_{z}} \Delta \delta_{\mathrm{z}}=-\mathrm{D}_{1} \Delta \delta_{\mathrm{z}}
$$

Where : $a_{1}^{v_{x}}=\frac{\partial a_{1}}{\partial v_{x}}, a_{1}^{\omega_{z}}=\frac{\partial a_{1}}{\partial \omega_{z}}, a_{1}^{\delta_{z}}=\frac{\partial a_{1}}{\partial \delta_{z}}=D_{1}$

Also, for the equilibrium of force along vertical axis, $T \cong G$ is an acceptable approximation in the case of hovering helicopter. The substitution of the above equations (6), (7) gives the following equations.

$$
\begin{aligned}
& \mathrm{I}_{z} \Delta \ddot{\theta}=T \mathrm{Y}_{\varepsilon} \mathrm{a}_{1}^{\mathrm{v}_{\mathrm{x}}} \Delta \mathrm{V}_{\mathrm{x}}+\mathrm{T} \mathrm{Y}_{\varepsilon} \mathrm{a}_{1}^{\omega_{z}} \Delta \dot{\theta}-\mathrm{T} \mathrm{Y}_{\varepsilon} \mathrm{D}_{1} \Delta \delta_{z} \\
& \frac{\mathrm{G}}{\mathrm{g}} \Delta \dot{\mathrm{V}}_{\mathrm{x}}=-\mathrm{T} \Delta \theta-\mathrm{T} \mathrm{a}_{1}^{\mathrm{v}_{\mathrm{x}}} \Delta \mathrm{V}_{\mathrm{x}}-\mathrm{T} \mathrm{a}_{1}^{\omega_{z}} \Delta \dot{\theta}+\mathrm{T} \mathrm{D}_{1} \Delta \delta_{z}
\end{aligned}
$$

Disregarding the terms $\mathrm{Ty}_{\varepsilon} \mathrm{a}_{1}^{\omega_{z}} \Delta \dot{\theta}$ and $T D_{1} \Delta \delta_{z}$ in view of their practically negligible influence on helicopter dynamics Ref.[1], and rearranging equations we get:

$$
\begin{aligned}
& \mathrm{I}_{\mathrm{z}} \Delta \ddot{\theta}=\mathrm{M}_{z}^{\mathrm{v}_{\mathrm{x}}} \Delta \mathrm{V}_{\mathrm{x}}+\mathrm{M}_{z}^{\omega_{z}} \Delta \dot{\theta}+\mathrm{M}_{\mathrm{z}}^{\delta_{\mathrm{z}}} \Delta \delta_{\mathrm{z}} \\
& \frac{\mathrm{G}}{\mathrm{g}} \Delta \mathrm{V}_{\mathrm{x}}=\mathrm{x}^{\theta} \Delta \theta+\mathrm{X}^{\mathrm{v}_{\mathrm{x}}} \Delta \mathrm{V}_{\mathrm{x}}
\end{aligned}
$$

Where: $\bar{M}_{z}^{\omega_{z}}=\frac{M_{z}^{\omega_{z}}}{I_{z}}, \bar{M}_{z}^{v_{x}}=\frac{M_{z}^{v_{x}}}{I_{z}}, \bar{M}_{z}^{\delta_{z}}=\frac{M_{z}^{\delta_{z}}}{I_{z}}, \bar{X}^{v_{x}}=-g a_{1}^{v_{x}}, X^{\theta}=-T$

Applying Laplace's transformation to the above equations, the following equations result:

$$
\begin{aligned}
& \left(\mathrm{s}^{2}-\overline{\mathrm{M}}_{\mathrm{z}}^{\omega_{\mathrm{z}}} \mathrm{s}\right) \Delta \theta=\overline{\mathrm{M}}_{\mathrm{z}}^{\mathrm{v}_{\mathrm{x}}} \Delta \mathrm{V}_{\mathrm{x}}+\overline{\mathrm{M}}_{\mathrm{z}}^{\delta_{\mathrm{z}}} \Delta \delta_{\mathrm{z}} \\
& \left(\mathrm{s}-\overline{\mathrm{X}}^{\mathrm{v}_{\mathrm{x}}}\right) \Delta \mathrm{V}_{\mathrm{x}}=-\mathrm{g} \Delta \theta
\end{aligned}
$$

The relation between the swash plate ring deflection $\delta_{z}$ and the helicopter pitch angle $\Delta \theta$ takes the form: 


$$
G_{H}(s)=\frac{\Delta \theta}{\Delta \delta_{z}}=\frac{\bar{M}_{z}^{\delta_{z}}\left(s-\bar{X}^{V_{x}}\right)}{s^{3}-\left(\overline{\mathrm{X}}^{V_{x}}+\bar{M}_{z}^{\omega_{z}}\right) s^{2}+\overline{\mathrm{X}}^{V_{x}} \bar{M}_{z}^{\omega_{z}} s+g \bar{M}_{z}^{V_{x}}}
$$

The coefficient of the helicopter transfer function are calculated and the transfer function describing the studied helicopter during hovering mode is finally:

$$
\mathrm{G}_{\mathrm{H}}(\mathrm{s})=\frac{\Delta \theta}{\Delta \delta_{z}}=\frac{-7(\mathrm{~s}+0.0185)}{\mathrm{s}^{3}+0.9915 \mathrm{~s}^{2}+0.018 \mathrm{~s}+0.16}
$$

A fast investigation of the helicopter stability could be fulfilled by apply the Routh-Herwitz stability criteria, the helicopter is found to be unstable. The studied helicopter is equipped with an autopilot. The autopilot acts to stabilize the helicopter in the absence of pilot command signal. There are no available information about the construction and performance of the studied autopilot. Therefor a special effort is paid to stabilized the helicopter by introducing convenient controller.

\section{Autopilot Design}

The problem confronting automatic pilot designer is the conversion of the airplane into a stabilized platform. This is necessary to relieve the pilot of piloting on long hauls, improve bombing precision, support passenger comfort ,etc

\subsection{Design of Helicopter Autopilot}

The angles taken by the helicopter fuselage in space are sensed by central gyro, vertical gyro or artificial horizons, which produce electrical signals proportional to pitch and roll angles. These electric signals are the input signals to the autopilot system which gives the required output. Figure 8 shows the block diagram of the helicopter control system.

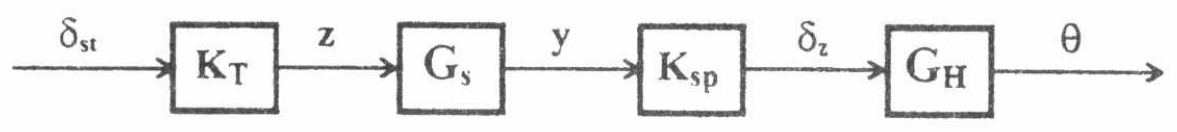

Figure (8) Block diagram of the helicopter with HSA

The mechanical transmission ratios $\mathrm{K}_{\mathrm{T}}$ and $\mathrm{K}_{\mathrm{sp}}$ are considered to be the forward gains, the gain $\mathrm{K}_{\mathrm{r}}$ is the mechanical transmission ratio between pilot stick and HSA input rod. The gain $\mathrm{K}_{\mathrm{sp}}$ is the mechanical transmission ratio between HSA output rod and swash plate, where: $\mathrm{K}_{\mathrm{T}}=0.12 \mathrm{rad} / \mathrm{m} \quad \mathrm{K}_{\mathrm{sp}}=1.4 \mathrm{~m} / \mathrm{rad}$. The overall helicopter transfer function $\mathrm{G}(\mathrm{s})$ is given as follows:

$$
G=\frac{-0.136(54.05 s+1)}{(0.02 s+1)\left(6.25 s^{3}+6.2 s^{2}+0.11 s+1\right)}
$$

The design procedure of helicopter control system is conducted in the following steps:

1- Analysis of system without any compensation.

2- Introducing a unity feedback element.

3- Adding suitable compensators. 


\subsection{HCS without Compensator}

The study of the transfer function of helicopter showed that it has two poles in the right hand side of the s-plane which indicates that the helicopter is unstable. Therefore, it should be stabilized by introducing a convenient controller.

\subsection{HCS with Unit Feedback and Forward Gain}

A first trial is carried out to stabilize the helicopter by adding a unity feedback loop and a forward gain $\mathbf{K}_{\mathbf{A}}$ Fig.9.

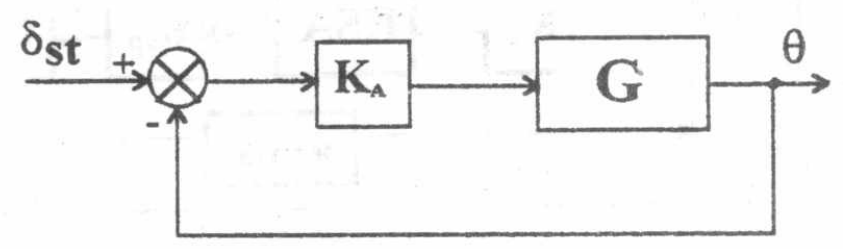

Fig.9. Block diagram of HCS with unit feedback and forward gain

The investigation of the system stability and its root locus showed that for the roots to be located in the left hand-side of s-plane, $\mathbf{K}_{\mathbf{A}}$ should lie in the range: $-42.48<\mathbf{K}_{\mathbf{A}}<-0.123$

The Study of the step response of the helicopter for different values of $\mathbf{K}_{\mathrm{A}}$ showed that:

1-The steady state error is increased when the gain $\mathbf{K}_{\mathrm{A}}$ is increased.

2-The over shoot and frequency of transient oscillations are increased by decreasing $\mathbf{K}_{\mathbf{A}}$

The gain $K_{A}$ is chosen to give the maximum damping; $K_{A}=-0.6215$.

\subsection{HCS with Compensator}

A proportional plus derivative compensator (PD controller)is introduced in the feedback path, where $\mathbf{H}=\mathbf{a}+\mathbf{b s}$, Fig. 10. The HCS with PD controller presented an over damped transient response with considerable steady state.

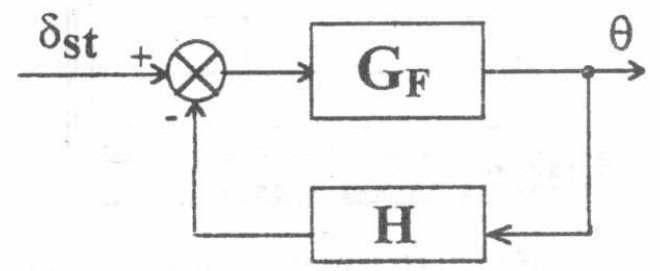

Fig. 10. Block diagram of HCS with PD feedback compensator

\subsection{HCS with Cascade Compensator}

The problem of increased steady state error could be solved by adding a proportional plus integral controller in the forward path as shown in Fig. 11. The numerical values of parameters a, b, c \& d of the PD and PI controllers were predicted by using the parameter estimator command, PE, available in the TUTSIM program. The PE command uses the simplex method 
to estimate the numerical values of these parameters, that minimize the integral square error;

$$
\mathrm{E}_{\mathrm{rr}}=\int_{0}^{t}\left(\delta_{\mathrm{st}}-\theta\right)^{2} \mathrm{dt}
$$

The step response of the HCS with autopilot (feedback PD compensator and forward PI compensator) is calculated and plotted in Fig. 12. This figure shows that the proposed compensators has improved both stability and steady state error problems.

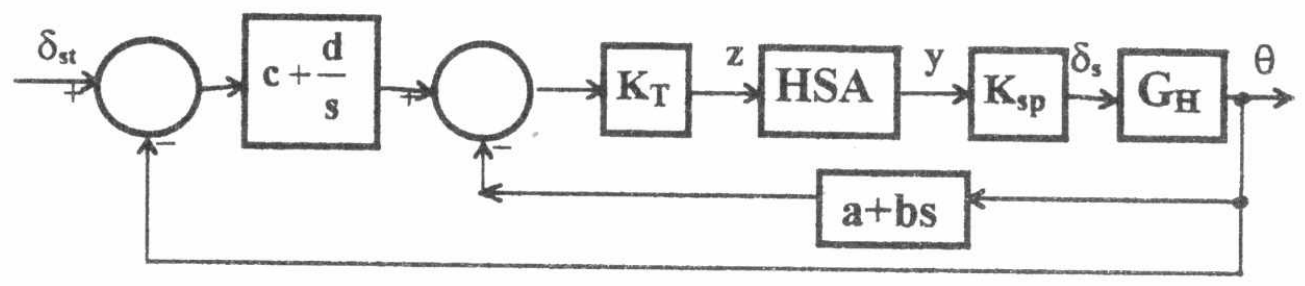

Fig. 11. Block diagram of HCS with the proposed PD and PI compensators

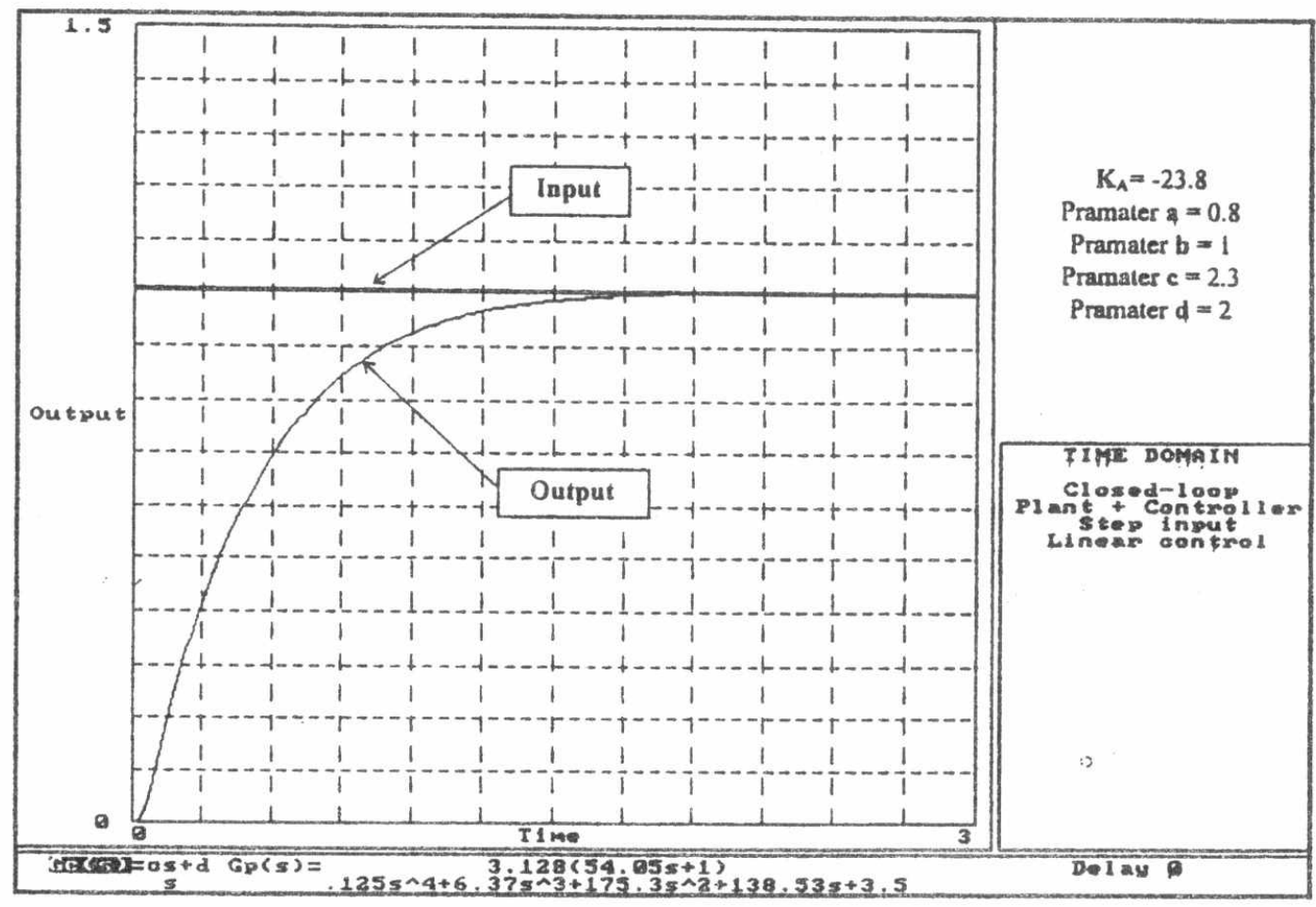

Figure (12) Step response of the HCS with PI and PD compensators.

\section{Effect of HSA Operational Parameters On Helicopter Stability}

\subsection{Interaction of HSA with the HCS}

The procedure of design of compensator, considered the effect of HSA as represented by a first order element. This model of HSA was deduced assuming that the HSA is operating unloaded in normal operating conditions. It does not introduce the effect of variation of any of the constructional and operational parameters, such as the internal leakage, variation of supply pressure and real loading conditions. 


\subsection{Effect of operating parameters on HSA performance}

The effect of constructional and operational parameters of the HSA on its dynamic behavior could be evaluated theoretically by using the developed simulation program.

\subsubsection{Effect of pressure level on the HSA}

The effect of supply pressure on the HSA performance was evaluated by calculating the step response of HSA for different pressure levels. The internal leakage resistance was kept constant; $\left(\mathrm{R}_{\mathrm{i}}=5 * 10^{18} \mathrm{Pas} / \mathrm{m}^{5}\right)$. The HSA presented an over damped step response. The settling time and rise time are found to decrease by increasing the supply pressure as shown in Fig. 13 .

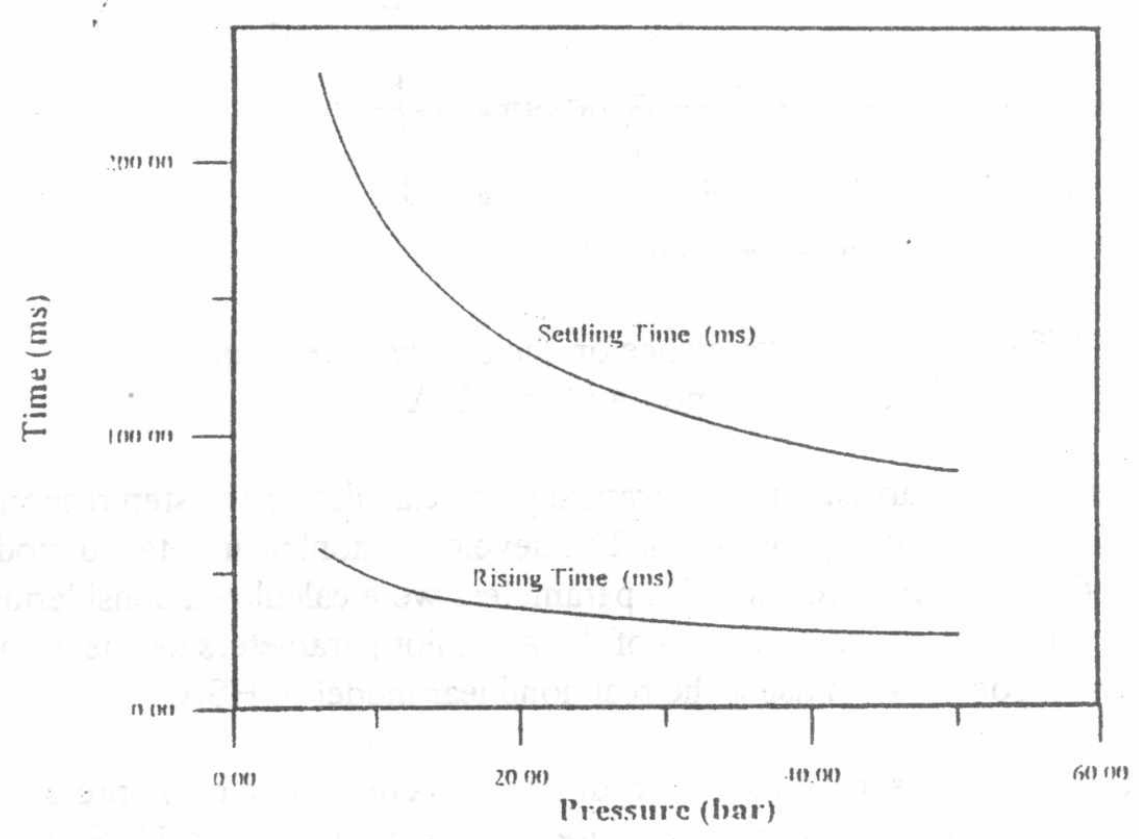

Fig. 13. Effect of supply pressure on the settling and rise times of HAS step response

\subsubsection{Effect of Internal leakage on HSA Performance}

The effect of internal leakage resistance on the performance of the HSA was evaluated theoretically by using the developed simulation program. The step response of HSA-to a step input of magnitude $z=0.5 \mathrm{~mm}$ is calculated for different values of internal leakage resistance. The supply pressure was kept constant $\mathrm{P}_{\mathrm{p}}=35 \mathrm{bar}$. The HSA presented an over damped step response associated with considerable steady state error, which decreases with increasing the leakage resistance as shown in Fig. 14.

\subsection{Effect of HSA Operational Parameters on helicopter stability}

The previous analysis showed that the variation of supply pressure and resistance to internal leakage have considerable effect on the static and dynamic bahavior of HSA. Here in, the effect of these two parameters on the performance of a helicopter equipped with HSA and autopilot 


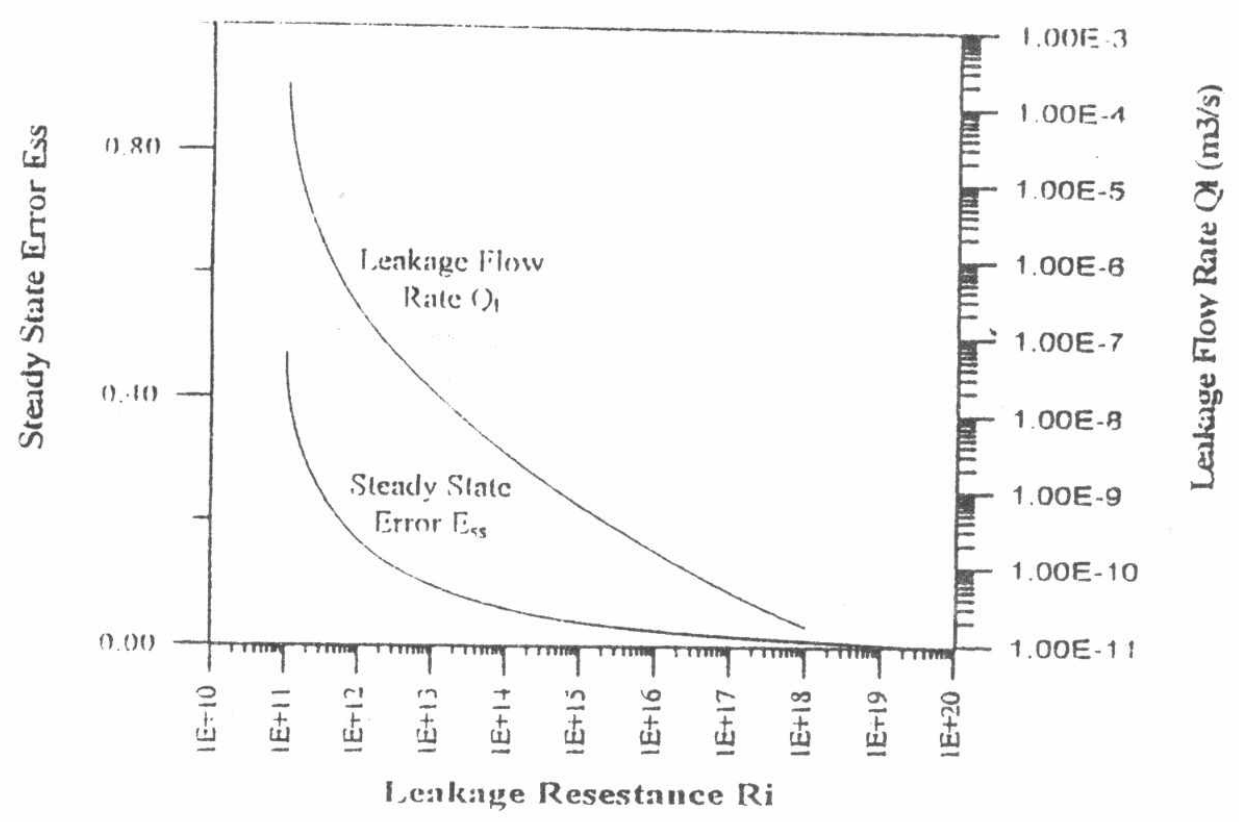

Fig. 14. Effect of leakage resistance on the steady state error of the transient response of the HSA

is evaluated. The evaluation is carried out theoretically by calculating the step response of helicopter, using the developed simulation program. The developed nonlinear detailed model of HSA is introduced in the program. The autopilot parameters were calculated considering the linear model of HSA. Therefor a tuning process of the autopilot parameters has been carried out to reach an optimum response, when using the real nonlinear model of HSA.

The step response of helicopter is calculated for different values of supply pressure and resistance to internal leakage. The simulation results are plotted in Figs. 15 and 16. Figure (15) shows the step response of helicopter calculated for different supply pressure levels. The study of this figure shows that the variation of supply pressure between 12 and 35 bar have significant effect on the performance of helicopter. For low pressure level $p<6$ bar, the hydraulic servo is disengaged and the helicopter is controlled manually by the pilot. Figure 16, shows the result of calculation of the step response of the helicopter for different values of resistance to leakage, keeping the constant supply pressure. This figure shows that decreases of resistance to leakage increases slightly the settling time and rise time. But no steady state error is observed due to the action of the integrating element of the autopilot. The decrease of leakage resistance below $10^{11}\left(Q_{1}=1.7510^{-5}\right)$, results in failure of operation due to the excessive power loses in hydraulic system.

\section{CONCLUSION}

The transient response of the HSA is evaluated experimentally and theoretically. A good agreement was found between the simulation and experimental result, which validate the simulation program. The effect of supply pressure and internal leakage on the behavior of the HSA is investigated theoretically by using the simulation program. The simulation result showed that: 


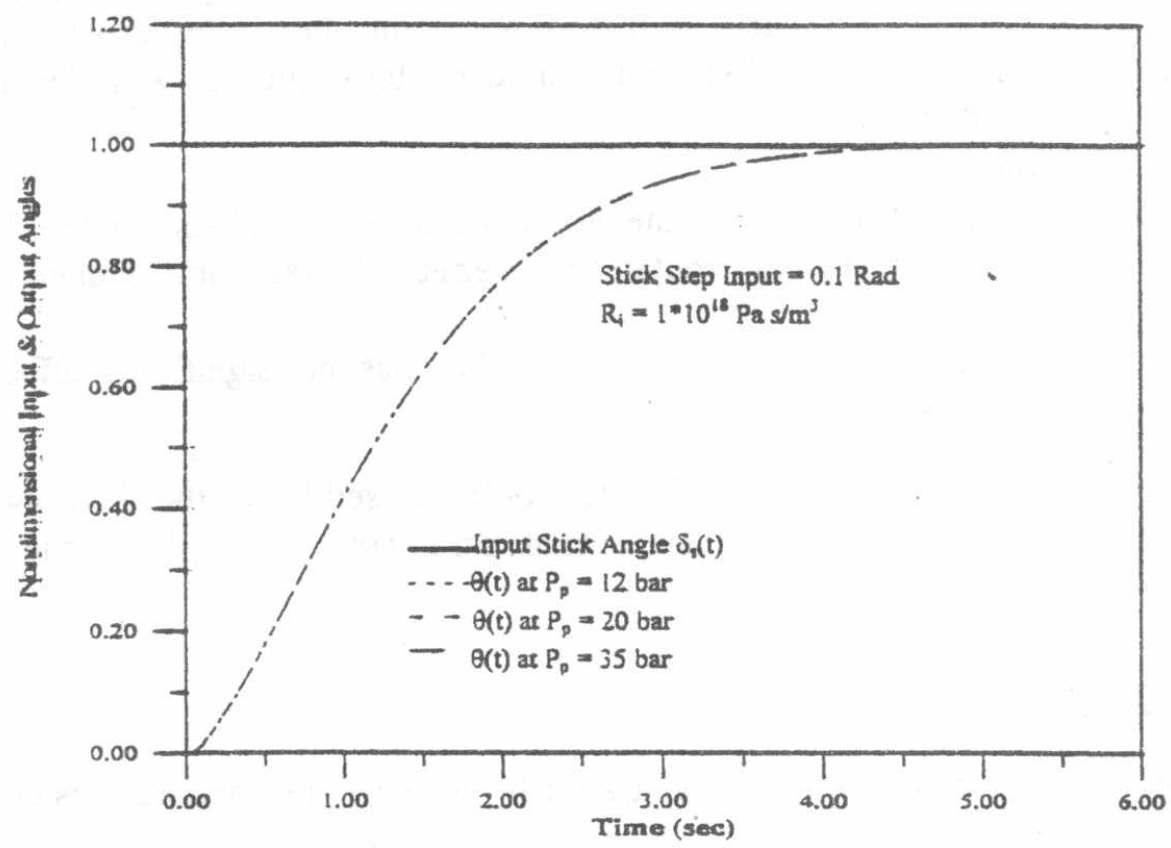

Fig.15. Effect of supply pressure on HCS behavior

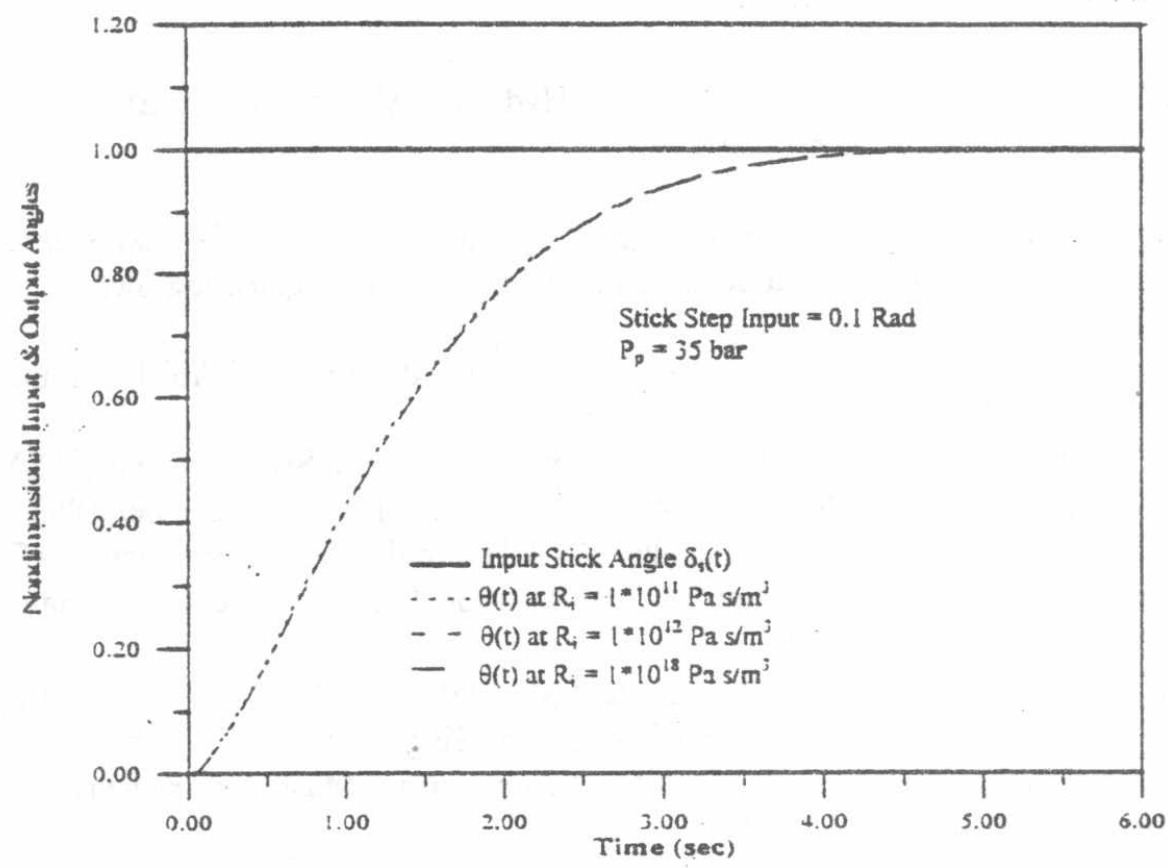

Fig. 16. Effect of leakage resistance on HCS behavior

1- The increase of supply pressure decreases the rise time and settling time.

2- The decrease of supply pressure bellows 5 bar leads to unstable response.

3- The increases of internal leakage introduces considerable steady state error.

A mathematical model for the helicopter was developed and used to deduce a transfer function for the helicopter during hovering. The helicopter was found to be dynamically unstable. The helicopter could be stabilized either through the pilot action or by using the autopilot. The studied helicopter is equipped with an autopilot. The real design of the autopilot is not known, 
therefor an autopilot was designed to assure the system stability. The proposed autopilot include a PD controller in the feed back loop and a PI controller in the forward path. The theoretical investigation of the dynamic behavior of a helicopter (equipped with the HSA and proposed controllers) showed that:

1-The helicopter is stable.

2-The steady state error, resulting from the effect of internal leakage in the HSA, is practically eliminated. This may be attributed to the effect of integrating element in the PI controller.

3-The variation of supply pressure from 12 to 35 bar has no significant effect on the transient response of the helicopter.

The developed simulation program of the helicopter could be used for further investigation of the effect of constructional and of other operational parameters of HSA on the dynamic behavior of helicopter.

\section{AKNOWLEGEMENT}

Thanks are attributed to Dr. Nagy Ragy Matta for his valuable help and advises during the preparation of this study.

\section{REFERENCES}

1 Rodden, J.J, "A Mathematical Representation of Hydraulic Mechanism", IEEE, Automatic Control, June 1960, PP 129-139. 331-338.

2 Marten, K.F., " Stability and Step Response of a Hydraulic Servo with Special Reference to Unsymmetrical Oil Volume Conditions", Jou. of Mechanical Engineering Sience, V12 ñ, 1970 PP.

3 Baz, A. et al, "Hydraulic Servo Valves with Built-in Turned Dampers," ASME, Fluidics Quarterly, V16, n5, April 17-20, 1978

4 Shearer, J, "Digital Simulation of a Coulomb-Damped Hydraulic Servo System", ASME, Journal of Dynamic Systems, Measurement, and Control, Vol. 105, December 1983.

5 Rabie, M.G. et.al Design of a New Controller for A Hydraulic Servomechanism", ASAT, $5^{\text {th }}$ Conference on Aeronautical Sciences and Aviation Technology, CAIRO, May 4-61993.

6 Blokelook, J., Automatic Control of Aircraft and Missiles, John Wiley, Inc., N.Y., 1972.

7 Dmitriyev, I. S, Yesaulov, S.Yu, "Control Systems for Single-Rotor Helicopters" Translation of Sistemy Upravleniya Odnvintovykh Vertolitov" Mash Inostroyeniye", Press, Moscow, 1969.

8 Layton, M.D, "Helicopter Performance" Library of Congress Cataloging in Publication Data ISBN 0-916460-39-8, 1984.

9 Mckillip, R.M., Perri, T.A, "Helicopter Flight Control System Design and Evaluation Using Controller Inversion Tehniques", $45^{\text {th }}$ Annual Forum of the American Helicopter Society, Boston, Mass., May 1989.

10 Prouty, "Helicopter Stability", Library of Congress Cataloging, 1990.

11 Tutsim, Users Manual IBM PC DOS, Meerman, Automation, Netherlands, 1990.

12 M.M.SAMIR, "Investigation of the Helicopter Dynamic Behavior With Special Reference to the Effect of Operational Parameters of Its Hydraulic Servoactuator", M.Sc. thesis, Military Technical College, Cairo, 1996. 